\title{
Seasonal variations in the incidence of photoparoxysmal response to stimulation among photosensitive epileptic patients: evidence from repeated EEG recordings
}

\author{
M A DANESI \\ From the Department of Medicine, College of Medicine of University of Lagos, Lagos, Nigeria
}

SUMMARY EEG records of photosensitive epileptic patients with repeated EEG recordings at different seasons of the year, were examined for the occurrence of photoparoxysmal response to photic stimulation (photoparoxysmal discharges (PPD)). Recordings in summer showed a lower incidence of PPD compared with recordings in other seasons. Recordings in winter showed a higher incidence of PPD compared with recordings in other seasons. Details of the 11 patients, each of whom had EEG recordings in summer and in winter confirmed the relative rarity of PPD in summer compared with winter. This reflects a lower cerebral neuronal excitability in summer compared with winter. Mechanisms for this, though not clear, may be related to an increased amount of environmental sunshine during summer and/or reduced temperature during winter.

Several studies comparing incidence of epileptic photosensitivity in different ethnic groups have shown that photoparoxysmal response to photic stimulation is relatively rare in Africans compared with Caucasians. ${ }^{1-4}$ The reason for this, apart from possible genetic influence, has not been clear. The theory of Stevens ${ }^{5}$ that differences in pigmentation of the eyelids may be relevant to the phenomenon was not confirmed by Bental ${ }^{6}$ in a survey of 70 normal African black albinos. Influence of an environmental factor was first suggested by Balzamo et $a l^{7}$ who observed a lower prevalence of photoparoxysmal discharges in photosensitive baboons (Papio papio) living in the North-Eastern savannah region of Senegal compared with those who live in the SouthWest forest region. Danesi ${ }^{4}$ observed in a large group of British epileptic patients, seasonal variation in the incidence of epileptic photosensitivity with photoparoxymal discharges relatively less common in

Address for reprint requests: Dr M A Danesi, Department of Medicine, College of Medicine of the University of Lagos, PMB 12003, Lagos, Nigeria.

Received 7 April 1987 and in revised form 15 December 1987. Accepted 23 December 1987 patients investigated in summer compared with patients investigated in winter, suggesting that environmental sunshine reduces susceptibility to photoparoxysmal discharges.

The present study was restricted to known photosensitive patients who had recordings done on more than one occasion and at different seasons. The aim was to determine if the season of EEG recording has any influence on the occurrence of photoparoxysmal response to photic stimulation in those photosensitive patients.

\section{Materials and methods}

The 49 patients studied were unselected epileptic patients who were referred for routine EEG recordings at the Department of Clinical Neurophysiology, The National Hospital for Nervous Diseases, Queen Square, London. All the patients had more than one EEG recording and showed evidence of laboratory photosensitivity during at least one of the routine EEG recordings. Both initial and repeat EEG recordings were done at various seasons of the year. Twenty two recordings were in summer, 35 recordings in winter, 17 recordings in spring and 16 recordings in autumn.

All the patients had been diagnosed as photosensitive because their EEG records showed evidence of photoparoxysmal discharges. Photoparoxysmal discharges (PPD) 
are generalised spike and wave discharges, consistently elicited by intermittent photic stimulation, not frequency locked to the stimulus and outlasting the stimulus train by at least 100 milliseconds. ${ }^{8}$ During the period of investigations all the patients were on treatment with routine anticonvulsive drugs and there was no evidence of change in therapy during this period. All the patients were diagnosed as having epilepsy because they had had more than one episode of non febrile seizures.

EEG records of the patients were examined and the proportion of the patients who showed evidence of photoparoxysmal discharges were obtained for the various seasons. The significance of the differences in the proportions of PPD between recordings in summer and winter was tested using chi-square test (Fisher's exact test, since the sample were small).

There were 11 patients who had EEG recordings done in summer and winter. Details of these patients including response to photic stimulation were obtained and recorded.

The routine EEG recordings at the National Hospital for Nervous Diseases were usually done in the waking state using a 16-channel EEG machine, and electrode placement was in accordance with the 10-20 system of the International Federation. ${ }^{9}$ Each recording included 3 minutes of hyperventilation as well as photic stimulation. The standard method of photic stimulation was used with the stimulation lamp placed directly in front of the patients' eyes at about 30 $\mathrm{cm}$ from the nasion in a darkened room. Stimulation was done in trains with flash frequencies ranging from 1 to $50 \mathrm{~Hz}$.

\section{Results}

Seasonal differences in incidence of PPD The lowest incidence of photoparoxysmal discharges occurred among summer recordings $(9 \cdot 1 \%)$ and the highest incidence occurred among winter recordings $(96 \%)$. Incidence among spring recording was $70.5 \%$ and autumn recordings was $68.75 \%$. These incidence are shown in a histogram and plotted against average periods of bright sunshine in the London area (Kew) for different seasons (obtained from the meteorological department).

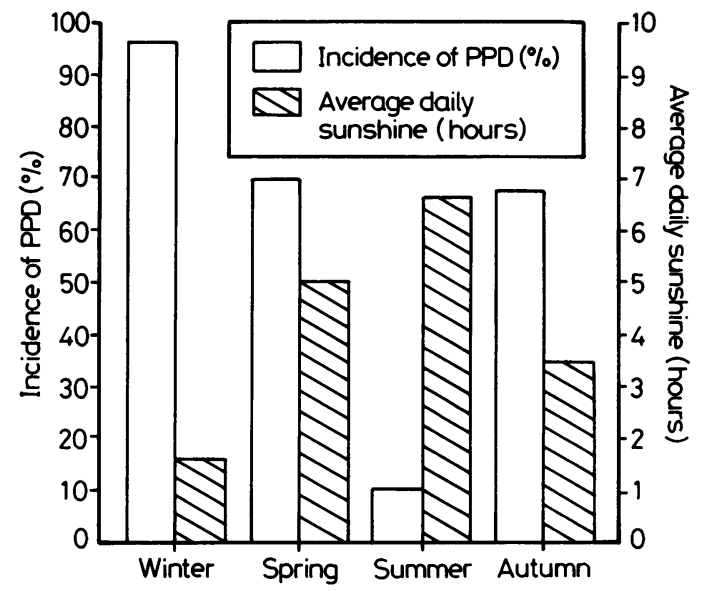

Fig: Histogram of PPD plotted against average periods of bright sunshine in different seasons.

Summer and winter recordings The incidence of PPD among summer recordings was significantly lower than the incidence among winter recordings $(\mathrm{p}<$ 0.01 ). Details of the 11 patients who had EEG recordings done both in summer and winter are shown on the table. The details confirmed the relative rarity of PPD in summer compared with winter.

\section{Discussion}

The results showed a clear seasonal variation in the percentage of EEG recordings containing photoparoxysmal discharges, with the lowest percentage occurring in summer and the highest percentage in winter, and a significantly lower percentage in summer compared with winter. There was no evidence of change in therapy or compliance during the periods of study. Although the majority of the 11 patients studied in detail were females, there was no evidence

Table Details of the 11 patients who had EEG recordings in summer and winter

\begin{tabular}{|c|c|c|c|c|c|c|}
\hline \multicolumn{3}{|c|}{ Patient'ṣ data } & \multicolumn{2}{|c|}{ EEG in summer } & \multicolumn{2}{|c|}{$E E G$ in winter } \\
\hline Age & $\operatorname{Sex}$ & Type of epilepsy & Date & Result of IPS & Date & Result of IPS \\
\hline $\begin{array}{l}42 \\
44 \\
17\end{array}$ & $\begin{array}{l}F \\
F \\
F\end{array}$ & $\begin{array}{l}\text { GE } \\
\text { GE } \\
\text { GE }\end{array}$ & $\begin{array}{r}4 \text { July } \\
27 \text { Aug } \\
1 \text { June } \\
28 \text { July }\end{array}$ & $\begin{array}{l}\text { NAD } \\
\text { NAD } \\
\text { NAD } \\
\text { NAD }\end{array}$ & $\begin{array}{l}23 \mathrm{Dec} \\
13 \mathrm{Jan} \\
22 \mathrm{Feb}\end{array}$ & $\begin{array}{l}\text { PPD* }^{*} \\
\text { PPD* } \\
\text { PPD* }\end{array}$ \\
\hline 20 & $\mathbf{F}$ & GE & $\begin{array}{l}5 \text { July } \\
16 \text { Aug }\end{array}$ & $\begin{array}{l}\text { NAD } \\
\text { NAD }\end{array}$ & $10 \mathrm{Dec}$ & $\mathrm{PPD}^{*}$ \\
\hline 16 & $\mathbf{F}$ & GE & $\begin{array}{l}6 \text { July } \\
30 \text { July }\end{array}$ & $\begin{array}{l}\text { PPD* } \\
\text { NAD }\end{array}$ & $30 \mathrm{Jan}$ & NAD \\
\hline $\begin{array}{l}14 \\
13 \\
30 \\
20 \\
15 \\
19\end{array}$ & $\begin{array}{l}\mathrm{F} \\
\mathbf{M} \\
\mathrm{F} \\
\mathbf{M} \\
\mathbf{M} \\
\mathrm{F}\end{array}$ & $\begin{array}{l}\text { GE } \\
\text { GE } \\
\text { PE } \\
\text { PE } \\
\text { PE } \\
\text { PE }\end{array}$ & $\begin{array}{l}26 \text { June } \\
27 \text { June } \\
15 \text { Aug } \\
17 \text { Aug } \\
27 \text { June } \\
11 \text { June }\end{array}$ & $\begin{array}{l}\text { PPD* } \\
\text { NAD } \\
\text { NAD } \\
\text { NAD } \\
\text { NAD } \\
\text { NAD }\end{array}$ & $\begin{array}{r}7 \mathrm{Dec} \\
16 \mathrm{Feb} \\
22 \mathrm{Jan} \\
13 \mathrm{Jan} \\
8 \mathrm{Feb} \\
22 \mathrm{Feb}\end{array}$ & $\begin{array}{l}\text { PPD* } \\
\text { PPD** } \\
\text { PPD** } \\
\text { PPD* } \\
\text { PPD** } \\
\text { PPD* }\end{array}$ \\
\hline
\end{tabular}

IPS $=$ intermittent photic stimulation. 
of influence of sex on the occurrence of PPD, as male patients showed similar seasonal variations (the three male patients all had PPD in winter and none had PPD in summer). A possible influence of menstrual cycle was therefore excluded.

The relative rarity of PPD among photosensitive patients investigated in summer probably reflects reduced cerebral neuronal excitability during this season. An earlier study ${ }^{4}$ found evidence suggesting reduced cerebral neuronal excitability in patients exposed to a large amount of environmental sunshine and a study of Papio papio in Senegal showed reduced prevalence of photoparoxysmal discharges in animals exposed to large amounts of sunlight. ${ }^{7}$ There is more sunshine in the summer when the average duration of daylight is over 16 hours compared with winter when average duration is less than 8 hours. The figures obtained from the meteorological department showed that the daily average duration of bright sunshine during summer in the London area (Kew) is 6.63 hours while that of winter is 1.55 hours. The overall average for the year is about 4 hours.

The mechanisms for this influence of sunshine are not clear but can be deduced from results of animal experiments which suggested that increased amounts of environmental sunshine increases the concentration of noradrenaline, and alpha adrenergic receptors in the brain. ${ }^{10}$ Noradrenaline, acting on alpha adrenergic receptors is a known inhibitor of spontaneous neuronal activities in the cerebral cortex..$^{11-13}$ There is also a theory that temperature changes may influence cerebral neuronal excitability, as evidenced by the observation that spike and wave may be induced by local cooling of the brain and cerebral neuronal excitation may be caused by hypothermia. ${ }^{14-16}$ This may also partially explain the high cerebral neuronal excitability in winter.

The observation of seasonal variation in paroxysmal response to photic stimulation in photosensitive patients requires further study and confirmation as it may have practical relevance in the investigation of suspected photosensitive patients. It is possible that when such patients have normal reaction to photic stimulation in summer, a repeat EEG recording in winter may elicit photoparoxysmal responses.

The patients in the present study were selected on the basis of laboratory photosensitivity only. Whether patients with clinical television epilepsy are less likely to show photoparoxysmal responses to photic stimulation in summer, or less prone to television induced seizures in summer compared with winter will require a careful prospective clinical study.

I am grateful to all the staff of the Department of Clinical Neurophysiology of the National Hospital for Nervous Diseases, Queen Square, for their won- derful cooperation during this study and to Professor Oyebande of the University of Lagos, who obtained from the Meteorological Department the exact sunshine figures for London area. This study was made possible by a fellowship grant from the Association of Commonwealth Universities.

\section{References}

1 Mundy Castle AC, McKiever BL, Prisloo T. A comparative study of the electroencephalogram of normal Africans and Europeans of South Africa. Electroencephalogr Clin Neurophysiol 1953;5:533-43.

2 De Graaf AS, Van Wyk Kotze TG, Claassen OA. Photoparoxysmal responses in EEG of some ethnic groups in Cape Peninsula. Electroencephalogr Clin Neurophysiol 1980;24:275-81.

3 Danesi MA, Oni K. Photosensitive epilepsy and photoconvulsive responses to photic stimulation in Africans. Epilepsia 1983;24:455-8.

4 Danesi MA. Geographical and seasonal variations in incidence of epileptic photosensitivity. Electroencephalogr Clin Neurophysiol (Abstr) 1985b;61:(3).

5 Stevens JR. The EEG spike signal of information transmission. Ann Neurol 1977;1:309-14.

6 Bental E. Observations on the electroencephalograms and photosensitivity in South Africa black albinos. Epilepsia 1979;20:593-6.

7 Balzamo E, Best J, Menini CH, Nasquet R. Excess light sensitivity in papio papio; its variation with age, sex, and geographical origin. Epilepsia 1975;16:267-70.

8 Reilly LR, Peters JF. Relationship of some varieties of electroencephalographic photosensitivity to clinical convulsive disorders. Neurology 1973;23:1050-7.

9 Jasper HH. The ten-twenty system of the International Federation. Electroencephalogr Clin Neurophysiol 1958;10:371.

10 Kafka MS, Wirz-Justice A, Waber D. Circadian and seasonal rhythm in alpha and beta adrenergic receptors in the rat brain. Brain Res 1981;207:19.

11 Krnjervic K, Phillis JW. Action of certain amines on cerebral cortical neurones. Br J Pharmacol 1963; 20:471-90.

12 Phillis JW, Koustopoulos GK. Activation of noradrenaline pathway from brain stem to rat cerebral cortex. Gen Pharmacol 1977;8:207-211.

13 Hoffer BJ, Siggins GR, Oliver AP, et al. Activation of pathways from locus coeruleus to rat cerebellar purkinje neurones. Pharmacological evidence of noradrenaline central inhibition. J Pharmacol Exp Ther 1973;184:553-69.

14 Lipp JA. Effects of hypothermia on electrical activities of the brain. Electroencephalogr Clin Neurophysiol 1964;17:46-51.

15 Suda I, Koizumi K, Brooks CM. Analysis of effects of hypothermia on central nervous system responses. $\mathrm{Am}$ J Physiol 1957;189:373-80.

16 Siegfried J, Ervin FR, Miyazaki Y, Mark VH. Local cooling of the central nervous system, 1, Neurophysiological studies on experimental animals. $J$ Neurosurg 1962;21:840-52. 